\title{
Enhanced degree of injury classification model: determination critical indicator and criteria degree of injury from Visum et Repertum (Ver) in Pekanbaru, Indonesia
}

\author{
Mohd Hadyan Wardhana ${ }^{1 *}$ (D) Burairah Hussin ${ }^{1}$, Abd Samad Bin Hasan Basari ${ }^{1}$ and Dedi Afandi $^{2}$
}

\begin{abstract}
Background: This study aims to obtain criteria and indicator as parameters to determine the degree of injury from Visum et Repertum (VeR). The approach is done by adopting quantitative descriptive learning from VeR data. This study is conducted to retrieve the independent variable, either one variable or more. The techniques applied in this study are (Analytical Hierarchy Process) AHP and (Logistic Regession) LR to the opinion of experts according to the VeR data for a new knowledge discovery. Survey methods used in Bhayangkara Hospital Pekanbaru in the period from 2013 until 2016. The data sample used in this study is secondary data which are injury data from VeR.

Result: The finding of this study reveals that the model developed using the AHP and LR has good ability to determine and analyze the parameters for the degree of injury from VeR based on experts' opinion.

Conclusions: The LR results also showed the physical factors that influence the degree of injury. Which are Respiration Rate (RR) and Systolic Blood Pressure (SBP). The higher Respiration Rate (RR) indicated the degree of injury is lighter. On the contrary, the lower Respiration Rate (RR) indicated the degree of injury is rising. While, the higher Systolic Blood Pressure (SBP) explained the degree of injury is lighter, and the lower level of Systolic Blood Pressure (SBP) explained the degree of injury level increase.
\end{abstract}

Keywords: Analytical Hierarchy Process, Logistic Regression Analysis, Degree of Injury, Medical Forensic, Trauma Care

\section{Background}

Visum et Repertum $(\mathrm{VeR})$ is a written statement made by the physician upon written request (official) by the investigators about the medical examination of the human person either alive or dead, part of the human body from the findings and interpretations were made under oath in the interests of justice. Thus, Visum et Repertum also serves as a liaison between medical science and jurisprudence. Visum et Repertum of abuse cases can explain the type of violence and patterns of injury that happens to someone, also load the information or the opinion from the doctors about the result of medical examinations. Meanwhile, legal practitioners can

\footnotetext{
* Correspondence: hadyanwardhana89@gmail.com

${ }^{1}$ Faculty of Information and Communication Technology, University

Technical of Malaysia Malacca, 76100 Durian Tunggal, Melaka, Malaysia

Full list of author information is available at the end of the article
}

also apply the valid legal rules to criminal cases that concerned to the human body.(Herkutanto, 2005; Afandi, 2008)

Visum et Repertum is not mentioned in the Criminal Procedure Code (Book of the Law from Criminal Law) or RIB (Indonesia Regulation updated), but only found in Statute 350 in 1937. In its development, on the Visum et Repertum Workshop in Jakarta in 1986 and other meetings, it has been agreed that written expert statements made by doctors for judicial are referred as Visum et Repertum.

Some of the things that will be outlined from the Visum et Repertum survivor are chronological events, the general condition of the patient, the injury found, the actions taken against the patient, the circumstances while in and after the treatment time. The conclusion 
shall describe the injuries, causes of violence and degree qualification of injuries.

An important part of Visum et Repertum is the degree of injury. Determining the degree of injury shall adjust to the degree of injury according to the formula qualification to Article 351, 352, and 90 the Code of Penal (Indonesian Penal Code).(Afandi, 2010) The third formulation of the article distinguishes the degree of injury suffered by victims into three types which are the minor injury, moderate injury, and severe injury.

The assessment of the degree of injury was subjective in nature, making it difficult to estimate the procurement of resources to deal with the injury. To address this, more objective scoring systems are developed. Some of these systems only consider aspects of anatomy such as Abbreviated Injury Scale (AIS), Injury Severity Score (ISS), and New Injury Severity Score (NISS). Others only consider physiological aspects such as Revised Trauma Score (RTS) and Coded RTS (CRTs).

It was found that the modification of other considerations to improve the precision of such Triss and Kampala Trauma Score. From all the above scoring system, only the ISS has been widely studied for forensic purposes. The entire study was conducted outside Indonesia, so it is not suitable for compliance with Indonesian law.

Differences in the degree of injury can use to assist the judge in determining the sentence for the defendant in court. Disagreement between examining from a physician can arise due to the differences level of knowledge and experience involved in the degree of injury evaluation process.

Results from studies in several government hospitals, private hospitals and enterprise hospitals in Jakarta showed that the average of $V e R$ has low-quality condition. This was obtained where the determination of the injury degree is one of the contributory factors to the low quality of $V e R$. This occurs because of misleading in concluding the degree of injury, so it will cause injustice to victims and perpetrators of criminal acts.(Afandi, 2010)

Currently, there are no clear definition or limitation criteria for the minor injury and moderate injury. Thus, a standard indicator is needed to assess the degree of injury. One proposed way to improve the objectivity of determining the degree of injury is to use computer-based information systems.

Development of computer-based information systems uses to classify the degree of injury automatically which perform by the acquisition of expert knowledge as a computer learning materials (Machine Learning). The initial stage of knowledge acquisition can start by developing the determinants of the degree of injury and factors that influence it. One of them uses the combination of Hierarchical Analytical Process (AHP) model and Logistic Regression models (LR) model.
Today, there are several methods used in the field of medicine to determine the degree of injury. To determine the degree of injury requires a reliable method of analysis based on the observation of medical parameters that can be available quickly without waiting for the result of the laboratory analysis. Practically there is no standard method for determining the degree of injury, unfortunately, some weaknesses exist.

Previously, the method to classify the trauma victims based on the severity of injury known as Injury Severity Score (ISS), which is adapted the value of the Abbreviated Injury Scale (AIS), which calculate the severity from anatomy. The ISS scores strongly correlate with the probability of survival for traumatized patients.

The weakness of ISS is limited for multiple injury to one body region, and it ISS will give equal weight to each body region. For example, AIS 4 score in the chest region will give different prognosis when compare with AIS 4 score in head region.(Wardhana \& Fatriah, 2018)

To improve the limitation of ISS, New Injury Severity Score (NISS) was found by calculating the quadrant of the three injuries that has the highest score of AIS whether it comes from another region. In addition, there are another combination factors between physiological and anatomical parameter which known as TRISS.

A single indicator is currently known as Trauma and Injury Severity Score (TRISS) has resulted in several percentage survival chances (prognosis). This confusion can be reduced by using a more objective evaluation system like Injury Severity Score (ISS), Revised Trauma Score (RTS), Trauma and Injury Severity Score (TRISS), New Injury Severity Score (NISS), etc. From the entire system, ISS, RTS, and Age has been the most frequently assessment systems that widely used is in the practice of forensic.(Theodoraki et al., 2010) A scoring system that has been tested and proven to be more objective than forensic doctors' opinion is TRISS. The formula of TRISS is quite complicated, so most people must use a calculator or a special program to calculate the value of TRISS. This limits the usefulness of TRISS. This is not to determine the degree of injury. Thus, it takes other appropriate indicators and criteria to determine it, so that the results will more accurate.

An Injury severity assessment method is important to predict and classify the injury degree. Differences in criteria used to assess the injury are necessary because it will have associated with possible mortality, reliability, cost, quality of life, and disability. TRISS has deficiency in describing injuries that occur until the problem does not consider the aspect of medical condition that already exist.

The prediction model that available today is not good enough to retrieve the specific result for determining the degree of injury classification, the data are obtained manually and has difficulties to evaluate it for the 
analysis process. But with the combination of AHP and LR is possible to provide an opportunity to increase the accuracy of trauma degrees by finding the most critical criteria for injury.

The study aims to propose the finding of critical indicator and criteria as parameters to determine degree injury classification model for medical aspect, especially in the field of forensic and analyze the physical factors that affect the degree of injury on $V e R$. The indicator and criteria evaluate based on three forensic experts from several hospitals.

This study will answer the following questions:

1. What are the critical indicator and criteria of degree injury on $V e R$ based on three experts?

2. What is the level of acceptance of parameters on the use of AHP and LR model?

3. What are the physical factors that affect the degree of injury on $V e R$ ?

\section{Methods}

This study is done by the adapted Quantitative Descriptive approach to $V e R$ data. This study was conducted to discover the value of an independent variable, either one variable or more variables (independent). The results obtained from this study was represented as qualitative data in the form of number. This study was conducted at Hospital Bhayangkara Pekanbaru in the period 2013 to 2016.

The population sample of data used in this study is secondary data. Which is $\mathrm{VeR}$ data injury where exist at RS Bhayangkara Hospital Pekanbaru. This data already fulfills the inclusion criteria of $V e R$ and consist of; Pro Justitia, introduction, report, conclusions and closing, and signed by the forensic expert and general practitioner who conducted in the examination process.

The sample in this study used random sampling method from $V e R$ data of survivor which is amount to 260 samples. The data collected comes from the victim of $\mathrm{VeR}$ results that exist in the forensic Bhayangkara Hospital Pekanbaru. The results of this study are presented in the form of diagrams, tables, and curves.

The research questions were answered using the quantitative descriptive statistical method that provides analysis of mean score, percentages, and frequency obtained by using Statistical Packages for Social Science Program (SPSS) version 24.0. For analyzing the number of consistency criteria and indicator from $\mathrm{VeR}$.

\section{Roadmap activity}

In achieving the objectives of this study, series of activities have been carried out as follow:
1. Identify candidate indicators that can be used to determine the degree of minor, moderate, severe injury through literature studies.

2. Obtaining and Analyzing indicators through the first study.

3. Determine the sample data be used.

4. Apply the AHP and LR methods to the sample data based on experts' opinion to discover knowledge.

5. Test and discuss the result.

\section{Results}

Determination of the degree of injury criteria and indicator is done by using Analytical Hierarchy Process (AHP). AHP begins with the process of determining alternative solutions (criteria and indicators) which determines the degree of injury by the bottom-up technique based on the results of three panels of forensic medical specialist (expert panel).

\section{Analytical hierarchy process (AHP)}

Analytical Hierarchy Process (AHP) is one of the decision support model that will analyzing and organizing complex multi-factor or multi-criteria problem into mathematical hierarchy.(Soliman et al., 2016). Hierarchy of values as a representation of a complex problem in a level structure where the first level is the goal, which follows the level factor, sub-criteria, and so on down to the last level. With a hierarchy, a complex problem can be incorporated into groups of groups that are then organized into a hierarchical form that will look more structured and systematic. The measurement is done by comparing the judgement from experts to derive priority ranking.(Saaty, 2008) Multi criteria decision making can be used to improve classification accuracy which deal with large datasets. The results of AHP are the priorities of alternatives. These priorities can be used for the best alternative purpose. It will forms as vector of weights for expressing the critical ranking of alternatives.(Keren \& Hadad, 2016)

Step - step arrangement that used in AHP method follows:

1. Develop a hierarchy of problems encountered.

2. Determining the priority of the elements.

a. The first step in setting priorities element is making a comparison in pairs, that is comparing the elements in pairs according to the criteria in the provision by using the matrix form

b. Fill in pairwise matrix matrices i.e. by using numbers for represents the relative importance of one element

c. Synthesis. 
Considerations to pairwise comparison in synthesis to gaining overall priority.

1) Sums up the values of each column on the matrix.

2) Divide each value of the column by total the corresponding column to obtain normalization of matrices.

3) Summing the value of each matrix and dividing it by the number of elements for getting the average score.

4) Measure consistency.

a) Multiplying the value in the first column with the relative priority of the first element, the value in the second column with priority relative second element, and so on.

b) Summing up each row.

c) The result of the sum of the rows is shared with its relative priority elements concerned.

d) Divide the above results by many elements are there, the result is called eigenvalue.

The determination of the weight for each indicator and criteria is done by using pairwise comparison analysis with the scale of measurement in the form of the original number from 1 to 9 . The consistency of weight determination by the expert is evaluated by using the ratio of consistency ratio. If the results of pairwise comparisons provide consistency ratio value $<0.1$, then weighting by the experts have performed consistently and the value of weights assigned has met the logical framework.

\section{Logistic regression (LR)}

Logistic regression is method for classifications that analyze the multivariate statistical data.(Liu et al., 2014) Logistic regression is frequently applied in many areas in the field of medicine and healthcare in terms of classification and binary outcome.(Hosmer \& Lemeshow, 2000; Penny \& Chesney, 2008) Logistic regression technique is a modeling in mathematical approach that is used to describe the correlation and the relation between several explanatory variables. This technique discover as the most popular model in medical.(Dreiseitl \& Ohno-Machado, 2002)

The nature of the dependent variable in logistic regression is usually dichotomous such as 0 or 1.(Kavzoglu et al., 2014) This technique usually used to predict the outcome from a set of variables that may be continuous.(Raghavendra \& Srivatsa, 2011) Value of 1 will be taken by the dependent variable with $P$ as the probability of success or 0 as the value of probability of failure 1-P.

This kind of variable also called Bernoulli (or binary) variable. Suppose there are $\mathrm{n}$ experimental runs with binary response y ( 0 or 1$)$ that will rely on a set of variables in the regressor X1.X2... Xk. if we show $\mathrm{y}=1$ as a success and $y=0$ is a failure. Modeling is the response the average $\mathrm{P}(\mathrm{Xi})$. Where $\mathrm{P}(\mathrm{Xi})$ is the probability of success and $\mathrm{Xi}$ will show the covariates or regressors on the data point.

\section{Discussions}

\section{Weight and consistency calculation for body region}

Determine the weight of injury degree criteria using AHP method. The first step in determining the weight of the criteria for determining the degree of injury using the AHP method is to compare between the elements with a scale of one to nine. The comparison is by making a matrix of comparisons in pairs of criteria as shown in Table 1.

Indicators on Table 1 shown the rank of body Regio which is represent as:

- $\mathrm{A} 1=$ Head and Neck;

- $\mathrm{A} 2$ = Face;

- $\mathrm{A} 3=$ Chest;

- $\mathrm{A} 4=$ Abdomen;

- $\mathrm{A} 5=$ Extremities (Arm, Leg, Feet, Hand).

- A6 = External;

Scales codes that used to determine indicator and criteria on body Regio is set to be 6 levels of include:

- 1 = both elements are equally important;

- 3 = one element is slightly more important than the other;

- $4.5=$ one element is more important than the other;

- $6=$ one element is clearly more important, essential than other elements;

- 7.5 = one element is essential than any other element;

- 9 = values between two values of adjacent considerations;

Table 1 provides the pairwise matrix for the body Regio based on the most critical rank from the three experts.

Table 1 Pairwise comparison criteria and indicator

\begin{tabular}{lllllll}
\hline Expert $(1,2,3)$ & A1 & A4 & A3 & A2 & A5 & A6 \\
\hline A1 & 1 & 3 & 4.5 & 6 & 7.5 & 9 \\
A4 & 0.333 & 1 & 3 & 4.5 & 6 & 8 \\
A3 & 0.222 & 0.333 & 1 & 3 & 4.5 & 6 \\
A2 & 0.167 & 0.222 & 0.333 & 1 & 3 & 5 \\
A5 & 0.133 & 0.167 & 0.222 & 0.333 & 1 & 3 \\
A6 & 0.111 & 0.133 & 0.167 & 0.222 & 0.333 & 1 \\
Column sum & 1.967 & 4.856 & 9.222 & 15.056 & 22.333 & 31 \\
\hline
\end{tabular}


Table 2 Normalized column summary

\begin{tabular}{lllllll}
\hline & A1 & A4 & A3 & A2 & A5 & A6 \\
\hline A1 & 0.508 & 0.618 & 0.488 & 0.399 & 0.336 & 0.290 \\
A4 & 0.169 & 0.206 & 0.325 & 0.299 & 0.269 & 0.242 \\
A3 & 0.113 & 0.069 & 0.108 & 0.199 & 0.201 & 0.194 \\
A2 & 0.085 & 0.046 & 0.036 & 0.066 & 0.134 & 0.145 \\
A5 & 0.068 & 0.034 & 0.024 & 0.022 & 0.045 & 0.097 \\
A6 & 0.056 & 0.027 & 0.018 & 0.015 & 0.015 & 0.032 \\
\hline
\end{tabular}

The summarization above was obtained from the three expert panels which are consist of two Forensic Specialist and General Doctor.

From Table 1 showed that the most critical indicator based on experts' results are Head and Neck, followed by Abdomen, Chest, Face, Extremities, and External.

After the number of columns is determined, then the next step is to divide the number in Table 1 with the number of each column, to form a normalized matrix. The table below will continue to the next step. The normalization matrix is shown in Table 2 .

Average from each row above will be calculated to generate the weight for each parameter. Matrix multiplication is done to obtain the weight value. The example of the calculation is as follows:

$$
\begin{aligned}
A 1= & (0.508+0.618+0.488+0.399+0.336 \\
& +0.290) / 6=0.43982 .
\end{aligned}
$$

the calculation is done until A6, so the priority table shown in Table 3 below.

The next step is to find consistency matrix, the matrix consistency is obtained from pairwise comparison matrix multiplication Table 1 with average priority weight in Table 3. Consistency matrix is shown in Table 4.

To determine the consistency vector. This is done by dividing the number of consistency matrix in Table 4 with the value of average that has been obtained in Table 3. for example,

$$
2.979 / 0.43982=6.77
$$

so, the vector consistency is shown in (Table 5):

Table 3 Average and weight matrix priority

\begin{tabular}{ll}
\hline $\begin{array}{l}\text { Average } \\
X\end{array}$ & Weight \\
\hline 0.43982 & $W$ \\
0.25170 & 0.50928 \\
0.14740 & 0.21946 \\
0.08543 & 0.11501 \\
0.04832 & 0.07025 \\
0.02733 & 0.04871 \\
\hline
\end{tabular}

Table 4 Matrix consistency table

\begin{tabular}{l} 
ax \\
\hline 2.979 \\
1.720 \\
0.967 \\
0.532 \\
0.292 \\
0.169
\end{tabular}

After the consistency vector value is determined. It is necessary to calculate the values of two other things, namely $(\lambda)$ max and Consistency index (CI) before the last consistency ratio can be calculated. The value of $(\lambda) \max$ is the average value of consistency Vector. Calculation of $\mathrm{CI}$ and CR according to Eqs. 1 and 2.

$$
\begin{aligned}
& \text { (ג) } \max =\text { Average }\{6.77+6.83+6.56+6.22+6.05+6.20\} \\
& =6.43903 C I=((\lambda) \max -n) /(n-1) C I \\
& =(6.43903-6) / 6-1)=0.08781
\end{aligned}
$$

The last step of the AHP is to determine the consistency of the ratio. The consistency ratio (CR) obtained by CI divided by Random Index (IR), (IR) is a direct function of the number of alternatives or systems under consideration (Table 6).

$$
\begin{gathered}
C R=C I / I R \\
C R=0.08781 / 1.24=0.07081
\end{gathered}
$$

Based on calculations that have been done where the $\mathrm{CR}$ for factor criteria used to show values smaller than 0.1 it can be concluded that the pairwise comparison is consistent so that the value of the evaluation factor criteria used in the case of this calculation can be used for calculation AHP. The other value also calculated with the same method.

The value of weight become the number to determine the rank of the Six Body Regio based on the AHP technique from three experts. It resulted that $\mathrm{A} 1, \mathrm{~A} 4, \mathrm{~A} 3$, A2, A5, and A6.

\section{Weight and consistency calculation for other criteria and indicators}

Based on the type of injury, it was classified into two types which are Penetrating (PE) injury and Blunt (BL) injury. Then the cause of injury also can divide into several types. For the Type of Penetrating injury (TPW), it can cause by Penetrating Incised Wound (PIW),

Table 5 Vector consistency table

\begin{tabular}{lllllll}
\hline $\operatorname{Lamda}(\lambda)$ & 6.77 & 6.83 & 6.56 & 6.22 & 6.05 & 6.20 \\
\hline
\end{tabular}


Table 6 Consistency ratio table

\begin{tabular}{lllllll}
\hline $\mathrm{CR}$ & 0.071 & 0.060 & 0.041 & 0.025 & 0.020 & 0.032 \\
\hline
\end{tabular}

Incised Wound (IW), Chop Wound (CW). For the Type of Blunt (TBW) injury consist of Abrasion (AB), Contusion (CO), Laceration (LA), Fracture (F), Bleeding (B).

Besides that, several criteria and indicators also being evaluated with the AHP. Which are Sex (S), Age (A), Glasgow Coma Scale (GCS), Systolic Blood Pressure (SBP), Respiration Rate (RR).

All the criteria and indicators above calculated with the same method as Body Regio Calculation is resulted in Fig. 1 below.

\section{Scoring system for criteria and indicators}

Scores that used to determine each indicator criteria set to be 5 levels of severity include:

- 0 = no injuries;

- 1 = Light;

- 2 = mild;

- 3 = moderate;

- 4 = heavy;

- 5 = very heavy;
For criteria and indicators in the form of numerical data injuries, the determination of the score is done by processing data in groups (Table 7).

If the criteria and indicators that have two values: No and Yes, the value score for No $=0$ and Yes $=5$.

$$
I=(M A X-M I N) / n
$$

The total score of total injury degree is determined by summing all the weighted multiplication and scoring of each criterion and indicators by using the formula.

$$
D I V=\left(\frac{\left(\sum_{i=1}^{i} w_{i} * V_{i}\right)}{5}\right) * 100
$$

Where

DIV $=$ Total score of injury degree

$\mathrm{Wi}=$ Weight for the $\mathrm{i}$-th criteria or indicator

$\mathrm{Vi}=$ Score for the $\mathrm{i}$-th criteria or indicator

Classification of the degree of injury is determined based on the distribution of DIV, DIV < quantile 1 categorized as the minor injury, the value of which is located between quantile DIV 1 and quantile 2 categorized as

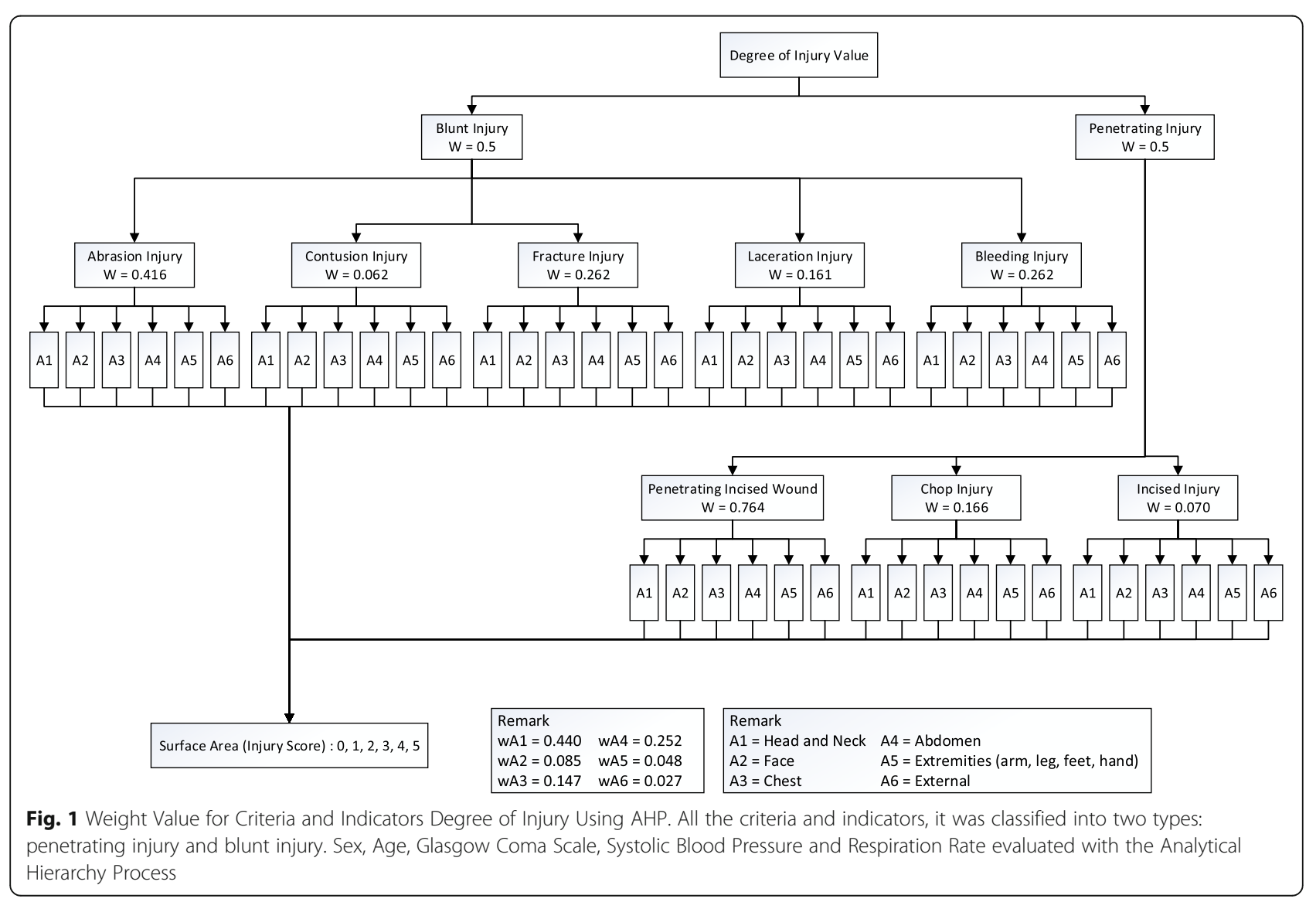


Table $\mathbf{7}$ Interpretation criteria and indicator score

\begin{tabular}{ll}
\hline Criteria / Indicator Score & Interval \\
\hline 0 & No Injury \\
1 & $\leq \operatorname{Min}(x)+i$ \\
2 & $(\operatorname{Min}(x)+i)-(\operatorname{Min}(x)+2 i)$ \\
3 & $(\operatorname{Min}(x)+2 i)-(\operatorname{Min}(x)+3 i)$ \\
4 & $(\operatorname{Min}(x)+3 i)-(\operatorname{Min}(x)+4 i)$ \\
5 & $\geq \operatorname{Min}(x)+4 i$ \\
\hline
\end{tabular}

moderate injury, DIV > quantile 3 value is classified as the severe injury.

\section{Determinants analysis degree of injury}

To determine the physical factors that affect the value DIV Binary Logistic Regression analysis using the formula:

$$
y=\frac{p}{1-p}=e^{b 1 * x 1+b 2 * x 2+b 3 * x 3+b 4 * x 4}
$$

Where:

$\mathrm{Y}=$ Probability of Injury Degree

$\mathrm{Y}=0$ if classified as minor or 1 is classified as moderate and severe injury

$\mathrm{P}=$ Probability

$\times 1=$ Sex

$\times 2=$ Age

$\times 3$ = Systolic Blood Pressure $(\mathrm{mmHg})$

$\times 4=$ Respiratory Rate (breaths per minute)

b1, b2, b3, b4 = Regression Coefficients

Based on the founding of the experts' panel, determination of criteria and indicators for the degree injury has identified and described in Fig. 1. Weight value on each

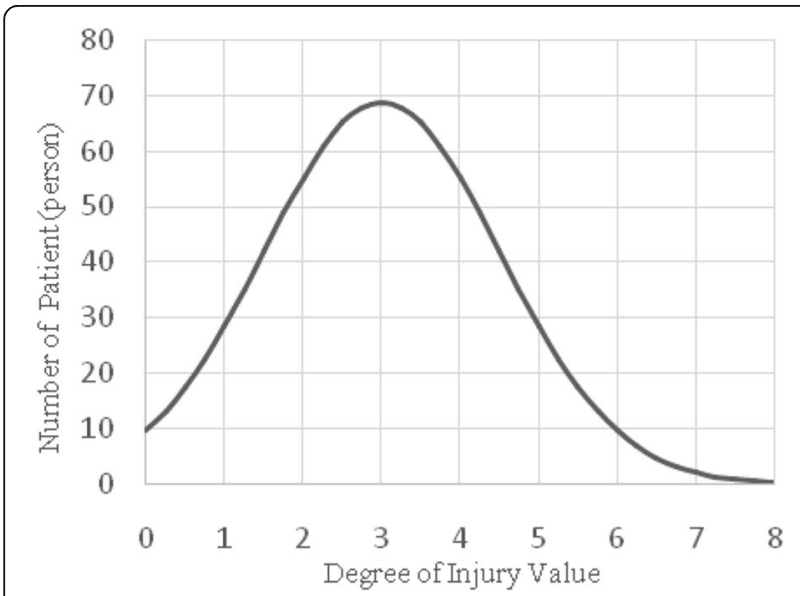

Fig. 2 Histogram Value the Degree of Injury (DIV). Classification of the degree of injury is determined based on the distribution of Degree of Injury Value criterion and indicators has fulfilled the consistency with relative value.

Based on the statistical analysis of the DIV value it is known that the maximum value is 6 and the minimum $=0$, so for the three classes interval value is 2 . Thus, for injury with DIV $<2$ categorized as the minor injury, DIVs between 2 and 4 categorized as moderate and DIV with $\geq 4$ categorized as a serious injury (Fig. 2).

Based on Chi-Square Test classification system provides a powerful relationship that is equal to $77.5 \%$ and significant at $95 \%$ confidence level so that it can be concluded that the classification system using AHP reliable to classify the degree of injury (Table 8 ).

The analysis result showed that the physical variables that affect the degree of injury are Systolic Blood Pressure (SBP) and Respiration Rate (RR). While age and sex had no significant effect on the degree of injury. Based on the results of logistic regression analysis showed that the blood pressure variables have a significant influence on the degree of injury which more severe degrees of injury in an injury case, it is directly proportional to the decrease in blood pressure.

Likewise, respiratory frequency variable that has a significant influence on the degree of injury, where the more severe degrees of injuries then directly proportional to the decrease in respiratory frequency. Value odd ratio for blood pressure is 14,087, which means that the decrease in the blood pressure $(\mathrm{mmHg})$ gives the possibility of more severe injuries by 14 -fold. While the respiratory rate has an Odd ratio of 0.968 which indicates that the decrease in respiratory frequency once per minute shows the odds of heavier injuries by 0.968 -fold. Variations in the degree of injury that can be explained by the logistic model are $82.13 \%$ while $7.87 \%$ are caused by other unknown factors. It was shown in Table 9 below.

According to the American Heart Association, normal systolic blood pressure ranging between $80-120$ $\mathrm{mmHg}$, and diastolic 60-80 $\mathrm{mmHg}$. Increased blood pressure can be found on the pain caused by trauma,

Table 8 Comparison of diagnostic grade classification result by the experts using ahp dvi

\begin{tabular}{lllll}
\hline FORENSIC & \multicolumn{2}{l}{ AHP PREDICTION } & Total \\
\cline { 2 - 4 } DIAGNOSTIC & Minor & Moderate & Severe & \\
\hline Light & 221 & 4 & 1 & 226 \\
Moderate & 0 & 24 & 0 & 24 \\
Heavy & 0 & 0 & 10 & 10 \\
Total & 221 & 28 & 11 & 260 \\
Chi-Square & & & & $483.901^{\mathrm{a}}$ \\
Contingency Coefficient & & & $0.811^{\mathrm{a}}$ \\
P-value & & & 0.000 \\
\hline asignificant at 95\% confidence level & &
\end{tabular}

asignificant at 95\% confidence level 
Table 9 Summary of logistic regression analysis ( $Y=0$ for DIV $<2$ and 1 for $>2$ )

\begin{tabular}{|c|c|c|c|c|c|c|c|c|}
\hline \multirow[t]{2}{*}{ Parameter } & \multirow[t]{2}{*}{ B } & \multirow[t]{2}{*}{ S.E. } & \multirow[t]{2}{*}{ Wald } & \multirow[t]{2}{*}{ df } & \multirow{2}{*}{$\begin{array}{l}\text { the } \\
p \text {-value }\end{array}$} & \multirow{2}{*}{$\begin{array}{l}\text { Odd Ration } \\
(\operatorname{Exp}(B))\end{array}$} & \multicolumn{2}{|c|}{ 95\% Cl.for EXP(B) } \\
\hline & & & & & & & Lower & Upper \\
\hline Constant & 2.645 & 1.140 & 5.384 & 1 & $.020^{\mathrm{a}}$ & 14.087 & 7.949 & 20.224 \\
\hline Systolic Blood Pressure & -0.033 & 0.012 & 7.325 & 1 & $.007^{\mathrm{a}}$ & 0.968 & 0.878 & 1.057 \\
\hline RR1 & -0.084 & 0.026 & 10.522 & 1 & $.001^{\mathrm{a}}$ & 0.919 & 0.646 & 1.193 \\
\hline SEX & 2.756 & 15.417 & 0.032 & 1 & $.858^{\mathrm{ns}}$ & 15.742 & 15.249 & 16.235 \\
\hline AGE & -0.008 & 2.500 & 0.000 & 1 & $.997^{\text {ns }}$ & 0.992 & 0.992 & 0.992 \\
\hline Chi-Square & & & & & & & & 187.397 \\
\hline the $p$-value & & & & & & & & 0.00 \\
\hline Nagelkerke R Square & & & & & & & & 0.8213 \\
\hline
\end{tabular}

${ }^{a}$ Note $=$ significant at the $95 \%$ level of confidence

$n s=$ not significant at the $95 \%$ level of confidence

this is due to the increment in the stimulation of baroreceptors.(Saccò et al., 2013)

Another study conducted predicted threshold values of systolic pressure in traumatized patients without brain injury that led to death that is $>190 \mathrm{mmHg}$ and > $180 \mathrm{mmHg}$.(Ley et al., 2012) The results of subsequent studies obtained the value of respiration rate in adults ranged between 18 and $20 \mathrm{~S}$ times per minute.(Braun, 1990) (Table 10).

Model prediction of the degree of injury is generated by using Logistic Regression

$$
y=\frac{p}{1-p}=e^{2.6545-0.033 S B P-0.084 R R}
$$

Where $\mathrm{Y}=$ Probability Degree of Injury,

SBP $=$ Systolic Blood Pressure $(\mathrm{mmHg})$,

$R R=$ Respiratory Rate (breaths per minute).

Figures 3 and 4 shows if $Y>0.35$ shows the degree of injury as severe injury, $0.15-0.34$ is classified as the moderate injury, while for less than 0.15 is classified as minor.

\section{Conclusions}

Model Determination of wound degree compiled by AHP approach in this study has a good ability to determine and classify the degree of injury on $\mathrm{VeR}$ based on expert opinion.

Table 10 Comparison result of diagnostic analysis degree of injury using Logistic Regression (LR)

\begin{tabular}{|c|c|c|c|c|}
\hline \multirow{3}{*}{\multicolumn{2}{|c|}{ Observed }} & \multicolumn{3}{|c|}{ Logistic Regression model prediction } \\
\hline & & \multicolumn{2}{|c|}{ Y } & \multirow[t]{2}{*}{ Percentage Correct } \\
\hline & & 0 & 1 & \\
\hline \multirow[t]{2}{*}{ Y } & 0 & 221.0 & 10.0 & 95.7 \\
\hline & 1 & 0.0 & 29.0 & 100.0 \\
\hline \multicolumn{2}{|c|}{ Percentage Correct } & 100.0 & 74.4 & 96.2 \\
\hline
\end{tabular}

The results of logistic regression analysis showed that the patients' physical factors that have an influence on the degree of injury are the respiratory rate and blood pressure. Where the higher the blood pressure indicates the degree of injury that is lighter while, the lower blood pressure indicates the degree of injuries increase. The higher frequency rate of respiratory indicates the degree of injury that is lighter and conversely the lower the frequency rate will rise the degree of injury.

Both parameters can be used to complement the predictive scoring system injuries that have been built using AHP. Nevertheless, the model can explain $82.13 \%$ while $7.87 \%$ of the variation of the degree of injury to the $V e R$ is still unknown.

There is no provision that regulates the examination that should be done by the doctor against the victim's life. The evidence is anything related to his criminal

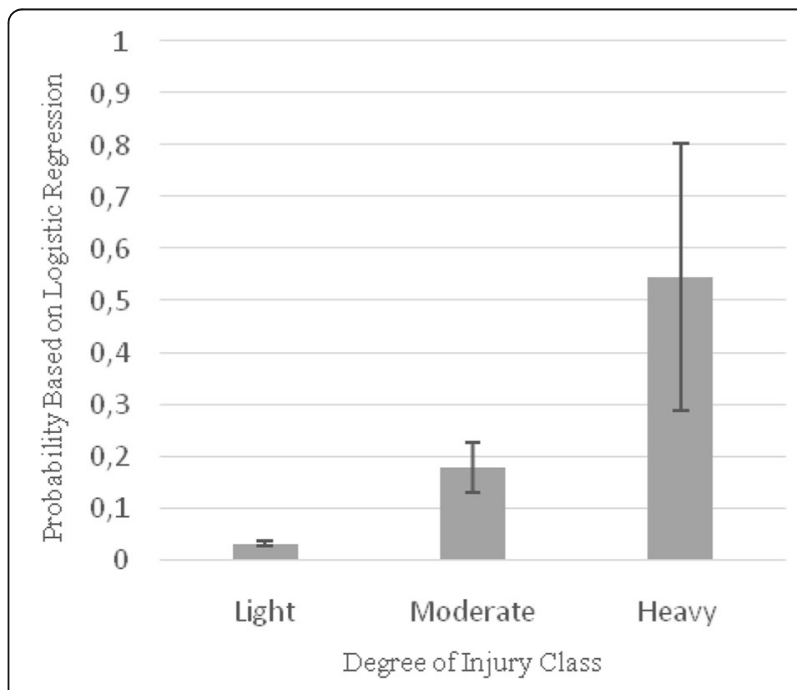

Fig. 3 Probability Class Degree of Injury Based on Logistic Regression Result. Degree of Injury Based on Logistic Regression, Fig. 3 shows if $Y$ $>0.35$ shows the degree of injury as severe injury, $0.15-0.34$ is classified as the moderate injury, while for less than 0.15 is classified as minor 


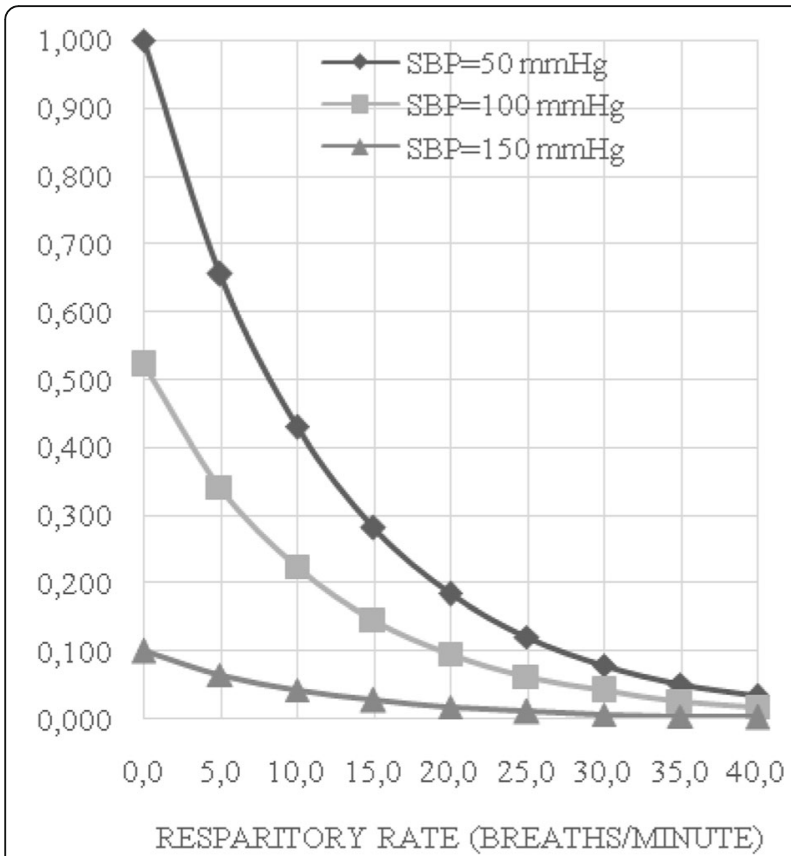

Fig. 4 Probability of Degree Injury (1 if DIV $\geq 2$ and - if DIV < 2). Blood pressure and respiratory rate can be used to scoring system injuries. Lower blood pressure indicates the degree of injury

case. While the person as a human being is still recognized as a legal subject with all rights and obligations.

The victim's medical examination is done by a doctor using forensic science that has been studied. However, it is not necessary to facilitate some data to be missed from the examination. The examination techniques on victim cases, openness, and other crimes, are in principle like other clinical procedures examined. The examination is done, physical examination and investigation if necessary. Examination of vital signs includes general conditions, level of consciousness, breath frequency, pulse frequency, and blood pressure. By using the indicators and criteria that have been obtained, the doctor will make measurements with the weight of the indicator is very important. Based on the results obtained from AHP.

With this, describe the degree of injury will be clearer, and good. This may have to be supported with an accurate description when describing the injuries found. The description in question is the region, the coordinates, the type of wound, the injured wound, the cut edge, the wound, the size of the wound, the network bridge, the objects and so forth.

\section{Abbreviations}

AHP: Analytical Hierarchy Process; AIS: Abbreviated Injury Scale; CRTs: Coded RTS; ISS: Injury Severity Score; ISS: Injury Severity Score; LR: Logistic Regession; NISS: New Injury Severity Score; NISS: New Injury Severity Score;
RR: Respiration Rate; RTS: RevisedTrauma Score; SBP: Systolic Blood Pressure; TRISS: Trauma and Injury Severity Score; VeR: Visum et Repertum

\section{Acknowledgements}

We thank to the Director of Bhayangkara hospital Pekanbaru for permission to publish this papaer. We are thankful for the technical support given by the Bhayangkara Hospital Pekanbaru at the Forensic Medicine and Medicolegal Departement for permission of collecting data from Visum et Repertum documentation.

\section{Availability of data and materials \\ Supporting data for the present article is available with the authors.}

\section{Authors' contributions}

First author contributes the conceptions and the design of work, data collecting activities, and data analysis, the Co-authors are the expert that act as the adviser from each aspect of background. The background of the expert consists of information and communication technology especially in mathematical and decision making. Co-author also the expert in forensic medicolegal who also contributes some ideas in forensic issues. All authors read and approved the final manuscript.

\section{Competing interest}

The authors declare that they have no competing interests.

\section{Ethics approval and consent to participate}

Ethical approval was obtained from the institute ethics committee at Ministry of Research and Higher Education University of Riau, Faculty of Medicine.

\section{Consent for publication}

Permission from the Committee of Institutional Ethics granted the privacy of individual publish.

\section{Publisher's Note}

Springer Nature remains neutral with regard to jurisdictional claims in published maps and institutional affiliations.

\section{Author details}

${ }^{1}$ Faculty of Information and Communication Technology, University Technical of Malaysia Malacca, 76100 Durian Tunggal, Melaka, Malaysia. ${ }^{2}$ Forensic Medicine and Medicolegal Studies Department, Faculty of Medicine, University of Riau, Pekanbaru 28133, Indonesia.

Received: 11 January 2018 Accepted: 15 May 2018

Published online: 24 May 2018

\section{References}

Afandi D (2008) Visum et Repertum Pada Korban Hidup. Pekanbaru. JIK (Jurnal IImu Kedokteran) 3(2):79-84

Afandi D (2010) Visum et Repertum Perlukaan : Aspek Medikolegal dan Penentuan Derajat Luka, Majalah Kedokteran Indonesia 60(4):188-195

Braun SR (1990) Respiratory Rate and Pattern. Clinical Methods: The History, Physical, and Laboratory Examinations (Vol. 10)

Dreiseitl S, Ohno-Machado L (2002) Logistic regression and artificial neural network classification models: a methodology review. J Biomed Inform 35(5-6):352-359. https://doi.org/10.1016/S1532-0464(03)00034-0

Herkutanto (2005) Improving the quality of Medicolegal reports in hospital through training emergency units physicians. Peningkatan kualitas pembuatan visum et repertum (VeR) kecederaan di rumah sakit melalui pelatihan dokter unit gawat darurat (UGD). JPMK 8(3):163-9

Hosmer DW, Lemeshow S (2000;(MARCH 2012)) Applied logistic regression. Wiley. https://doi.org/10.1080/00401706.1992.10485291

Kavzoglu T, Sahin EK, Colkesen I (2014) Landslide susceptibility mapping using GIS-based multi-criteria decision analysis, support vector machines, and logistic regression. Landslides. 11(3):425-439. https://doi.org/10.1007/s10346013-0391-7

Keren B, Hadad Y (2016) ABC Inventory Classification Using AHP and Ranking Methods via DEA. In: Second International Symposium on Stochastic Models in Reliability Engineering, Life Science and Operations Management (SMRLO), vol 2016. IEEE, pp 495-501. https://doi.org/10.1109/SMRLO.2016.87 
Ley EJ, Singer MB, Gangi A et al (2012) Elevated systolic blood pressure after trauma: tolerated in the elderly. J Surg Res. 177(2):326-329. https://doi.org/10. 1016/j.jss.2012.05.019

Liu D, Li T, Liang D (2014) Incorporating logistic regression to decision-theoretic rough sets for classifications. Int J Approx Reason 55(1):197-210. https://doi. org/10.1016/j.jijar.2013.02.013

Penny Kl, Chesney T (2008) A comparison of missing value imputation methods for classifying patient outcome following trauma injury. In: Proceedings of the International Conference on Information Technology Interfaces, ITI, pp 367-370. https://doi.org/10.1109/TT.2008.4588437

Raghavendra B, Srivatsa S (2011) Comparison of logistic regression and neural network model with and without hidden layer. uniascit.in 1(1):49-53

Saaty TL (2008) Decision making with the analytic hierarchy process. Int J Serv Sci. 1(1):83. https://doi.org/10.1504/IJSSCI.2008.017590

Saccò M, Meschi M, Regolisti G et al (2013) The Relationship Between Blood Pressure and Pain. J Clin Hypertens. 15(8):600-605. https://doi.org/10.1111/ jch. 12145

Soliman THA, Mohamed R, Sewissy AA (2016) A hybrid Analytical Hierarchical Process and Deep Neural Networks approach for classifying breast cancer. In: 2016 11th International Conference on Computer Engineering \& Systems (ICCES). IEEE, pp 212-219. https://doi.org/10.1109/ICCES.2016.7822002

Theodoraki E-M, Koukouvinos C, Parpoula C (2010) Neural networks for prediction of trauma victims' outcome. Comparison with the TRISS and Revised Trauma Score. In: Proceedings of the 10th IEEE International Conference on Information Technology and Applications in Biomedicine. IEEE, pp 1-4. https://doi.org/10.1109/TAB. 2010.5687802

Wardhana MH, Fatriah SH (2018) Degree of Injury on Visum et Repertum. Lupine Pubisher 1(1):1-2

\section{Submit your manuscript to a SpringerOpen ${ }^{\circ}$ journal and benefit from:}

- Convenient online submission

- Rigorous peer review

- Open access: articles freely available online

- High visibility within the field

- Retaining the copyright to your article

Submit your next manuscript at $\boldsymbol{s p r i n g e r o p e n . c o m ~}$ 